\section{Executive Functioning}

Casey R. Shannon ${ }^{1}$, Laura Shank ${ }^{2}$ and

Claire Thomas-Duckwitz ${ }^{1}$

${ }^{1}$ University of Northern Colorado, Greeley, CO, USA

${ }^{2}$ Rehabilitation Psychology and

Neuropsychology, Physical Medicine \&

Rehabilitation University of Michigan, Ann

Arbor, MI, USA

\section{Synonyms}

Executive processes; Executive system

\section{Definition}

A multifaceted construct involving a collection of interrelated, higher-level mental abilities believed to underlie independent goal-directed behavior, problem solving, and efficiency of knowledge acquisition. Abilities commonly associated with executive functioning include: initiation, planning, organization, working memory, attention, mental flexibility or shifting, inhibition, emotional regulation, and self-monitoring. Historically, this set of abilities was believed to be narrowly associated with the frontal lobe region of the brain; however, more recent research suggests that executive functioning relies on a number of networks that extend to other regions of the brain, including the frontal and posterior regions of the cerebral cortex, and the subcortex.

\section{See Also}

$\checkmark$ Executive Abilities

$\checkmark$ Executive Interview

- Frontal Lobe

- Frontal Lobe Syndrome

- Frontal Lobotomy

- Problem Solving

\section{References and Readings}

Goldstein, S., \& Naglieri, J. A. (Eds.). (2014). Handbook of executive functioning. New York: Springer.

Jurado, M. B., \& Rosselli, M. (2007). The elusive nature of executive functions: A review of our current understanding. Neuropsychology Review, 17(3), 213-233. doi:10.1007/s11065-007-9040-z.

Lezak, M. D., Howieson, D. B., Bigler, E. D., \& Tranel, D. (2012). Neuropsychological assessment (5th ed.). New York: Oxford University Press. 